\title{
Centro de Ensino de Ciências do Nordeste (CECINE) e uma história da formação de professores de matemática no Brasil
}

\author{
Marcelo Bezerra de Morais $^{1}$
}

\section{RESUMO}

Neste artigo, temos a intenção de apresentar uma versão histórica sobre a formação de professores de matemática ofertada pelo CECINE, levando em consideração mais estritamente o cenário do Rio Grande do Norte por ter sido o foco de nossos estudos. Para isso, lançamos mão de documentos constituídos a partir de uma operação historiográfica que mobilizou a História Oral como metodologia de pesquisa. Esta pesquisa, inserida em uma proposta de amplo espectro do Grupo História Oral e Educação Matemática, apresenta como apontamentos cursos ofertados pelo CECINE no qual buscou-se disseminar pelo Norte e Nordeste a Matemática Moderna e ainda a oferta de cursos de Licenciatura de Curta Duração em Ciências, que formou professores para atuar nessas regiões e ainda no Centro Oeste. PALAVRAS-CHAVE: História da Educação Matemática. Centros de Ciências. Formação de professores. Historiografia.

Northeast Science Teaching Center (CECINE) and a history of the teachers mathematics education in Brazil

\begin{abstract}
In this article, we intend to present a historical version of the teachers mathematics education offered by CECINE, specifically from state of Rio Grande do Norte, the focus of our studies. For that, we handle documents constituted from a historiographical operation from the Oral History as a
\end{abstract}

\footnotetext{
${ }^{1}$ Doutor em Educação Matemática. Universidade do Estado do Rio Grande do Norte, Mossoró, Rio Grande do Norte, Brasil. Orcid: $\underline{\text { https://orcid.org/0000-0003-4563-822X. E-mail: morais.mbm@ gmail.com. }}$
} 
research methodology. This research, inserted in a proposal of a broad spectrum of the Oral History and Mathematical Education Group (Ghoem), presents as notes courses offered by CECINE in which the aim was to disseminate the Modern Mathematics in the North and Northeast of Brazil and also the offer of Short Graduation courses in Sciences, which trained teachers for these regions and also the Midwest of Brazil.

KEYWORDS: History of Mathematics Education. Science Centers. Teacher training. Historiography.

Centro de Enseñanza de Ciencias del Nordeste (CECINE) y una historia de la formación de profesores de matemáticas en Brasil

\section{RESUMEN}

En este artículo, tenemos la intención de presentar una versión histórica de la capacitación de maestros de matemáticas ofrecida por CECINE, teniendo más en cuenta el escenario de Rio Grande do Norte, ya que fue el foco de nuestros estudios. Para eso, utilizamos documentos constituidos a partir de una operación historiográfica que utilizaba la Historia Oral como metodología de investigación. Esto estudio, insertada en una propuesta de un amplio espectro del Grupo de Historia Oral y Educación Matemática, presenta como notas los cursos ofrecidos por CECINE en los que el objetivo era difundir las Matemáticas Modernas en el Norte y Nordeste de Brasil y también la oferta de cursos de Grado a Corto Plazo en Ciencias, que capacitó a maestros para trabajar en estas regiones y en el Medio Oeste de Brasil.

PALABRAS CLAVE: Historia de la educación matemática. Centros de ciencias. Formación de profesores. Historiografía.

$$
* * *
$$

\section{Introdução}

Há anos o grupo de pesquisa História Oral e Educação Matemática (Ghoem), ao qual estamos vinculados, desenvolve pesquisas nas mais diversas regiões do Brasil sobre a história da formação e 
atuação de professores de matemática. Este exercício coletivo de pesquisa visa realizar um mapeamento cartográfico (e simbólico) sobre as possibilidades de formação de professores de matemática que existiram/existem no Brasil, buscando, talvez principalmente, os fluxos históricos que escapam aos ditos centros tradicionais de ensino, ou, em outros termos, às possibilidades formativas que aconteceram fora dos centros de formação popularmente conhecidos e tomados como principais ou únicos responsáveis pela formação institucional dos professores dessa disciplina (GARNICA, 2014; 2019).

Mobilizando principalmente a História Oral como metodologia de pesquisa, o Ghoem tem conseguido apresentar diferentes versões históricas e inúmeras possibilidades/mobilizações do que temos chamado "história da formativas de professores de matemática no Brasil", pondo em cena inúmeros cursos e projetos que existiram e ocuparam espaços de centralidade nesse fenômeno, mas, por motivos diversos, não são conhecidos ou lembrados ao remeter-se a ele ${ }^{2}$.

A partir de nossas pesquisas, que visavam compreender o fenômeno da formação de professores de matemática no estado do Rio Grande do $\mathrm{Norte}^{3}$, fomos levados, a partir de algumas narrativas, a conhecer o Centro de Ensino de Ciências do Nordeste (CECINE), posto que os relatos indicavam cursos ofertados por esse centro, até então desconhecido por nós e ainda pouco explorado nas pesquisas em História da Educação Matemática brasileira, e nos levou a questionar: qual o papel que essa instituição ocupou no cenário de formação de professores de matemática no Brasil e, em particular, no Rio Grande do Norte?

Com este artigo visamos, portanto, apresentar uma versão histórica da formação de professores de matemática ofertada pelo CECINE, levando em consideração especificamente o cenário do Rio

\footnotetext{
${ }^{2}$ Um caso exemplar, dentre outros que poderíamos citar a título de exemplo, é o da Campanha de Aperfeiçoamento de Difusão do Ensino Secundário (CADES), que ofertou formação aos professores de matemática em todo o país nas décadas de 1950 e 1960 e era pouco conhecida, já tendo sido objeto de muitos estudos no grupo. Para maiores informações sobre a CADES, recomendamos: Finato, Baraldi e Morais (2012), Baraldi e Gaertner (2013) e Miranda (2019).

${ }^{3}$ As pesquisas resultaram em nosso trabalho de mestrado e de doutorado (MORAIS, 2012; 2017).
} 
Grande do Norte por ter sido o foco de nossos estudos. Contudo, como o centro não atuou exclusivamente na formação de professores desse estado e os documentos aqui referenciados tampouco apontam dados apenas sobre esse estado, compreendemos que pomos ao leitor uma versão histórica que traz elementos, de modo mais amplo, sobre a formação de professores de matemática no Brasil.

Vale registrar que os documentos mobilizados para a constituição dessa versão histórica foram produzidos a partir de uma operação historiográfica que lançou mão da História Oral como metodologia de pesquisa, a partir das compreensões que vêm sendo produzidas e praticadas pelo Ghoem (GARNICA, 2019; GARNICA; FERNANDES; SILVA, 2011). Nesse sentido, compreendendo metodologia como uma articulação indissociável entre teoria e procedimentos práticos, constituímos um acervo de documentos narrativos produzidos a partir da oralidade e inúmeros documentos ditos "oficiais". Aqui, nos remeteremos a duas narrativas em particular, dos professores Raimundo de Freitas Melo e Almir da Costa Dantas, as quais podem ser acessadas na íntegra em Morais (2012) e Morais (2017), respectivamente. Além desses documentos, lançamos mão dos registros acessados no acervo pessoal do professor Raimundo Melo e ainda no que sobrou do acervo do CECINE, que pôde ser acessado na Universidade Federal de Pernambuco (UFPE) (esses documentos estão disponíveis em Morais (2012; 2017).

Assim, na sequência deste texto, conheceremos um pouco melhor o que foi o CECINE, bem como um pouco do contexto histórico de sua instituição. Dando seguimento, apresentaremos a versão histórica sobre como esse centro possibilitou formação aos professores de matemática do estado do Rio Grande do Norte e de diversos outros estados brasileiros, impactando fortemente nesse processo. Por fim, identificaremos alguns elementos que podem ser destacados sobre a atuação desse Centro. 


\section{Um primeiro preâmbulo: (re)conhecendo o CECINE}

Na década de 1960, o contexto brasileiro vivia uma realidade na qual era muito baixo o número de professores com alguma formação para atuar no ensino de Ciências. "Dados de 1965 mostram que a maioria do professorado do Ensino Médio (60\%) não detinha diploma universitário, outros eram normalistas (20\%), enquanto cerca de $20 \%$ improvisavam, sem formação de qualquer tipo" (ABRANTES, 2008, p. 177).

Umas das maneiras encontradas pelo Ministério da Educação e Cultura (MEC), para tentar melhorar o ensino e a produção científica no país, foi criar seis centros para formar professores para as diversas regiões do Brasil. Com isso, foram criados os CECIs: Centro de Ensino de Ciências do Nordeste (CECINE, instalado em Recife); Centro de Ensino de Ciências da Bahia (CECIBA, instalado em Salvador); Centro de Ensino de Ciências de Guanabara (CECIGUA, instalado no Rio de Janeiro); Centro de Ensino de Ciências de Minas Gerais (CECIMIG, instalado em Belo Horizonte); Centro de Ensino de Ciências de São Paulo (CECISP, instalado em São Paulo); e o Centro de Ensino de Ciências do Rio Grande do Sul (CECIRS, instalado em Porto Alegre).

A criação desses centros estava diretamente ligada à intenção de motivar o desenvolvimento da ciência que havia sido deflagrado em todo o país já na década de 1950. Naquela década, "a ciência e a formação de pessoal qualificado passam a ser vistas como elementos fundamentais para o progresso" (ABRANTES, 2008, p. 149 e 150), impulsionando, por exemplo, a criação, em 1951, do Conselho Nacional de Pesquisa (CNPq) e da Campanha Nacional de Aperfeiçoamento de Pessoal de Nível Superior (CAPES) -, bem como alertando para a necessidade urgente de formação dos professores das áreas de ciências experimentais (Ciências, Biologia, Física, Química e Matemática) para atuar no Ensino Médio, que, na época, compreendia o ginásio e colegial. (SILVA, 2012). 
O CECINE foi o primeiro dos seis centros, a ser criado pelo MEC, em 1965, com "o objetivo de promover a melhoria da qualificação de professores do ensino básico, sobretudo da rede pública" (SILVA, 2012), nos oito estados que, à época, compunham a região Nordeste do país (Pernambuco, Rio Grande do Norte, Paraíba, Ceará, Maranhão, Piauí, Sergipe e Alagoas). Após algum tempo, a responsabilidade por formar os professores dos estados da região Norte (Pará, Amazonas, Amapá, Rondônia, Roraima e Acre) passou ao CECINE. A área de atuação do CECINE ficou claramente diferenciada da dos demais CECIs, contrariando o desejo muito forte, nesse período, de impulsionar o desenvolvimento da Região Nordeste, que levou, inclusive, à criação da SUDENE, no ano de 1959.

A SUDENE foi criada com o objetivo de alavancar o desenvolvimento da região Nordeste, muito defasada em relação ao restante de todo o País. A SUDENE tinha, então, como responsabilidade indicar "diretrizes de uma política de desenvolvimento regional, às quais deveriam subordinar-se todos os investimentos federais no Nordeste, e atuar como órgão no planejamento e na coordenação dos investimentos federais na região" (FERNANDES, 2011, p. 118). Este órgão era ligado diretamente à Presidência da República, com sede também em Recife ${ }^{4}$.

Como apontado, os CECIs foram instituídos pelo MEC, mas este órgão não foi o executor direto dos programas, o que ficou a cargo de agências regionais, cumprindo a ele prover recursos financeiros e técnicos para desenvolver a educação e a ciência.

O MEC aparentemente permitia que os CECIs produzissem ciência, sem, necessariamente, possuírem uma estrutura rígida. No entanto, os objetivos desses centros eram "dar assistência permanente aos professores de ciências exatas e naturais; promover seminários, debates e conferências sobre temas relacionados com o aprimoramento do ensino das ciências exatas e naturais"; promover "cursos destinados a aprimorar

\footnotetext{
${ }^{4}$ Maiores informações sobre a SUDENE e as relações dessa superintendência com a educação da Região Nordeste, ver Fernandes (2011).
} 
os conhecimentos dos professores e aperfeiçoar as técnicas de ensino; estimular clubes de ciências e feiras de ciências, estimular a formação de associação de professores de ciências"; criar e "manter uma biblioteca especializada; promover concursos destinados a premiar professores e alunos; realizar convênio com estabelecimentos oficiais e particulares, tendo em vista o aprimoramento do ensino de ciências"; oferecer cursos de treinamento para "professores nas técnicas de improvisação do material científico; manter uma filmoteca especializada para o empréstimo de filmes às escolas"; averiguar a "boa aplicação do material científico emprestado ou doado às escolas; editar livros e periódicos sobre o ensino de ciências"; bem como "realizar inquérito sobre o ensino de ciências nas escolas do Estado" (MAURÍCIO, 1992, p. 45).

Outra agência que passou a atuar próxima a esses centros foi o Instituto Brasileiro de Educação, Ciência e Cultura (IBECC), estando quase que diretamente vinculado com o CECISP, ao qual ficou a incumbência de realizar a tradução de livros vindos dos Estados Unidos da América e aos centros coube "a tarefa de disseminá-los entre os professores. Vale ressaltar que, com exceção da criação da filmoteca, ficou documentado que todas as atribuições dos CECIs foram cumpridas pelo CECINE” (SILVA, 2012, p. 9). Os livros americanos da área de Matemática que o IBECC traduziu foi o School Mathematics Study Group, mais conhecido como SMSG.

Por ter sido experimental, criado seis meses antes dos demais, o CECINE conseguiu financiamento de agências importantes para o seu funcionamento como a Universidade Federal de Pernambuco (UFPE), a SUDENE, e a Fundação Ford. "Esta última fez um aporte de US\$150 mil para o período de 1965/1968”. A SUDENE entrou com "suporte financeiro para a contratação de parte da equipe e bolsas para professores passarem nove meses à disposição do CECINE. A universidade forneceu o espaço, os laboratórios e parte da equipe", enquanto o "Ministério da Educação forneceu fundos para bolsas e outras despesas” (MAURÍCIO, 1992, p. 18). 
Assim, possuindo recursos financeiros para funcionar tranquilamente, o CECINE passou a oferecer cursos para formar professores dos oito estados do Nordeste ${ }^{5}$.

\section{Uma história: formação de professores de matemática e o CECINE ${ }^{6}$}

Com a incumbência de ofertar formação aos professores das áreas de ciências, o CECINE atuava primordialmente formando professores para atuar no ensino de Matemática, Física, Química, Biologia e Ciências. Sobre as formações ofertadas para os professores da área de Matemática, o primeiro registro que podemos fazer é que o centro do Nordeste ofereceu uma capacitação para professores em dezembro de $1965^{7}$, quando o centro encaminhou à Universidade Federal do Rio Grande do Norte (UFRN) “informações e ficha de inscrição para o curso de verão de Matemática que ocorreria em fevereiro de 1966. Tal curso teria lugar em Salvador, Bahia, e propunha-se a abordar tópicos de Matemática Moderna”. Entretanto, não se têm notícias de alguém da UFRN ter participado desse curso oferecido pelo CECINE, pois nesse período ainda não existia o Instituto de Matemática na Universidade, e os professores da "Escola de Engenharia estavam muito mais preocupados em realizar aprofundamentos em assuntos relativos à matemática aplicada” (BRITO; CRUZ; FERREIRA, 2006, p.96).

Além desse momento intensivo, o CECINE ofereceu ainda outro curso, com duração mais longa, nos anos de 1967 e 1968, que capacitou pelo menos dois professores do Rio Grande do Norte, um de Mossoró e outro de Natal, os professores Raimundo de Freitas Melo e Evaldo Rodrigues de Carvalho, respectivamente. Apesar dos dois professores terem realizado esse curso no CECINE, ambos concordam sobre a disposição de que apenas um representante de cada área e de cada Estado era escolhido, conforme seus

\footnotetext{
${ }^{5}$ Esses dados também podem ser encontrados no relatório da UNESCO de 1968, "National Center for Research and Development in Science Teaching". (UNESCO, 1968).

${ }^{6}$ Esse texto traz inúmeras referências ao "Tomo Travessias", um dos volumes de nossa tese de doutorado (MORAIS, 2017), na qual todos os documentos aqui referenciados podem ser acessados.

${ }^{7}$ Ver o documento do CECINE encaminhado à UFRN sobre o curso intensivo (Registro $A X$ no Tomo Travessias).
} 
relatos $^{8}$. Entretanto, talvez para esse curso, da área de Matemática, tenham ido dois professores pelo Rio Grande do Norte.

O professor Raimundo lembra que houve uma confusão na seleção, pois, ao ser escolhido, questionaram sobre sua escolha por ele só possuir o colegial, e foram, inclusive, com a reclamação para a justiça. Entretanto, no final de 1967, a Fundação Rockefeller, financiadora do curso, decidiu que ele iria pelo Estado. Já o professor Evaldo recorda que ficou sabendo do curso por meio de um amigo que trabalhava na SUDENE, um dos órgãos dentre os que financiavam as atividades do CECINE. Os dois professores comentam que o curso tinha como objetivo formar professores multiplicadores, os quais, ao retornarem aos seus estados, deveriam formar outros professores a partir do material que haviam estudado.

O professor Evaldo, ao retornar a Natal, ainda formou alguns professores (GUTIERRE, 2008), mas o professor Raimundo não: ele voltou e continuou a lecionar, talvez pela quantidade de atividades que assumiu, pois, quando retornou, tornou-se diretor do Anexo II do Centro Educacional Jerônimo Rosado, onde também ensinava, e começou a lecionar na União Caixeiral.

O curso do qual os professores participaram, como indicado, foi financiado pela Fundação Rockefeller, instituição americana que visa, dentre outras coisas, colaborar com a educação em países estrangeiros, e também seguiu as perspectivas da Matemática Moderna.

Os idealizadores dessa abordagem, que ficou, mais tarde, conhecida como Movimento Matemática Moderna (MMM), estavam preocupados com o descompasso entre o ensino superior e o secundário, e pretendiam desenvolver uma alternativa para desvincular-se da matemática pautada apenas na memorização de processos. Segundo essa proposta, a matemática seria ensinada de forma lógica, revelando-se o raciocínio por trás do método, o que favoreceria a compreensão.

\footnotetext{
${ }^{8}$ Os relatos dos professores podem ser acessados, na íntegra, nos trabalhos de Morais (2012) e Gutierre (2008).
} 
Essa abordagem lógica já era mobilizada para ensinar geometria no ensino secundário. Desse modo, a principal mudança deveria dar-se nas disciplinas de Aritmética, Álgebra e Trigonometria. O MMM surge, inicialmente, como proposta de reforma do ensino secundário, mas logo volta-se também ao ensino primário, pensando ser primordial fazê-lo, posto que, neste nível, os alunos ainda não tinham os "vícios" comuns da memorização. Essa proposta impactou não apenas os métodos de ensino, mas também os conteúdos a serem ensinados, quando se passou a atribuir grande importância à axiomatização, às estruturas algébricas, à lógica e aos conjuntos (VALENTE, 2008; COUSIN, 2011; SOUZA; GARNICA, 2012).

É nesse período que são criados, no Brasil, os primeiros grupos de estudo e pesquisa na área do ensino de matemática, pautando-se nas ideias da Matemática Moderna, como, por exemplo, o Grupo de Estudos do Ensino de Matemática (GEEM), coordenado pelo professor Oswaldo Sangiorgi, em São Paulo ${ }^{9}$.

Os treinamentos para professores oferecidos pelo GEEM, grande divulgador das ideias e ideais da Matemática Moderna, eram divididos em estágios: no primeiro via-se Teoria dos Conjuntos e nos segundo e terceiro, Álgebra Linear. O GEEM foi também responsável pela criação de outros grupos de estudos, um dos quais em Santos/SP (batizado de GEEM'(linha)). Outro exemplo seria o Núcleo do Estudo e Difusão do Ensino de Matemática $(\text { NEDEM })^{10}$, criado no estado do Paraná, na década de 1960, coordenado pelo professor Osny Antonio Dacol, que "conscientizou um grupo de professores a fazer pesquisa sobre o Ensino Moderno da Matemática” (SEARA, 2005, p. 12). Outros grupos que colaboraram para a disseminação da Matemática Moderna foram o Grupo de Estudos de Ensino de Matemática de Porto Alegre (GEEMPA), criado em Porto Alegre, e o Grupo de Estudos e Pesquisas em Educação Matemática (GEPEM), com sede no Rio de Janeiro.

\footnotetext{
${ }^{9}$ Para maiores informações sobre o grupo GEEM, ver Baraldi (2003), Valente (2006) e Lima (2006).

${ }^{10}$ Para maiores informações sobre o NEDEM, ver Seara (2005).
} 
O MMM foi muito forte nas regiões Sul e Sudeste do país, tendo também tido os seus reflexos no Nordeste, e no Rio Grande do Norte, especificamente. Nesse estado, a SUDENE foi uma das grandes responsáveis pela disseminação dos ideários da Matemática Moderna que "interferiram na formação de professores de matemática, de modo a divulgar, por um lado, os ideais do MMM relativos à linguagem da teoria dos conjuntos e à estrutura algébrica como suporte de toda a matemática”, e por outro lado, "a representação da matemática como o suporte necessário ao desenvolvimento tecnológico, desenvolvimento este que possibilitaria a industrialização da sociedade, o que vai ao encontro dos ideais presentes na fundação da SUDENE” (BRITO; GUTIERRE, 2007, p. 8).

Acreditando, assim, ser a Matemática Moderna a base para a propulsão da ciência, essa Superintendência investiu em sua divulgação em toda a região Nordeste, tendo o CECINE como um dos meios para isso, por estarem consonantes em suas propostas.

Além dos financiamentos já mencionados, o CECINE beneficiouse, ainda na década de 1970, dos acordos entre o MEC e a USAID - os famosos acordos MEC/USAID ${ }^{11}$-, neste caso, voltados ao financiamento para a formação de professores nos cursos de Licenciatura de Curta Duração que estavam sendo criados.

Os cursos de Licenciatura de Curta Duração, que também receberam fartos recursos desses acordos, distinguiam-se dos cursos de Licenciatura Curta criados no final da década de 1960. Esses últimos, devido à grande necessidade de pessoas com formação para atuarem no ensino, tinham como objetivo graduar em curto prazo um número maior de professores para

\footnotetext{
${ }^{11}$ Os acordos do MEC com a agência americana USAID para o financiamento de materiais didáticos, cursos, entre outras coisas no País foram alvo de críticas por legitimar uma transformação modernizadora no país, ocasionando o direcionamento de sua racionalidade. Durante o regime militar, acordos do MEC com a USAID (que ficaram conhecidos como acordos MEC/USAID), envolvendo US\$ 15 milhões, favoreceu a indústria da educação. Esses acordos ficaram conhecidos, principalmente, pela existência de diversos acordos sigilosos que só vieram a se tornar públicos em 1966, como o acordo entre essas e o Conselho de Cooperação Técnica da Aliança para o Progresso (CONTAP), o MEC-CONTAP-USAID, "que previa assessoria para a expansão e o treinamento do quadro de professores do ensino de nível médio no Brasil". Por conta desses acordos, "o sistema de educação do País como um todo foi modificado, gerando" as reformas do ensino superior em 1968 e do ensino de primeiro e segundo grau em 1971. (ABRANTES, 2008, p. 191).
} 
atuarem no Ensino Médio. Entretanto, nem a criação dessa modalidade de formação, nem os exames de suficiência, que vigoravam desde 1946, foram ainda suficientes para suprir a demanda do constante crescimento das escolas com cursos ginasiais e colegiais no país. Nesse mesmo período, o Conselho Federal de Educação (CFE) autorizou o funcionamento de ginásios polivalentes, ou ginásios direcionados para o trabalho, que funcionariam com cursos técnicos em nível ginasial, e delegou ao Programa de Expansão e Melhoria do Ensino Médio (PREMEM) a tarefa de realizar a construção de espaços adequados para essas novas escolas, entre 1968 e 1972.

O PREMEM, criado pelo decreto 63.914, de 28 de dezembro de 1968, tinha como objetivo "incentivar o desenvolvimento quantitativo, a transformação estrutural e o aperfeiçoamento do ensino médio"12, e seria mantido com recursos públicos, federais e estaduais, e fontes internas e externas extraorçamentárias. No seu regulamento de criação previa-se, entre outras ações, que o programa seria responsável por administrar os projetos nacionais que visassem o treinamento e aperfeiçoamento de todos os professores para o ensino médio, além de construir um ginásio polivalente modelo em cada uma das capitais brasileiras, instalar e manter centros de treinamentos de professores de ciências, selecionar bolsistas para realizarem aperfeiçoamentos no exterior e organizar serviços de assistência técnica educacional.

Com essas incumbências, visando principalmente o trabalho nos ginásios polivalentes, a responsabilidade mais difícil e importante que o PREMEM tinha era colocar essas instituições para funcionar, o que, consequentemente, implicava arranjar corpo docente suficiente e adequado para atuar no ensino, cabendo lembrar que era necessária uma formação específica, posto que, nessas novas escolas, buscar-se-ia "conciliar as exigências da educação geral básica com a iniciação vocacional”13, voltado

\footnotetext{
${ }^{12} \mathrm{O}$ decreto de criação do PREMEM foi publicada na íntegra na Documenta 96 de dezembro de 1968 e pode ser acessados no Tomo Travessias (Registro $C W$ ).

${ }^{13}$ O projeto que cria as Licenciaturas de Curta Duração do PREMEM foi publicado na íntegra na Documenta 109 de dezembro de 1969 e pode ser acessado no Tomo Travessias (Registro CX), além dele, trazemos também os Planos
} 
para o trabalho, ressaltando-se que não era um ginásio profissional, mas visava proporcionar aos alunos experiências que desenvolvessem atitudes e capacidades de trabalho para preparar os jovens para o contexto de sociedade industrial em que viviam.

É nesse contexto, então, que o PREMEM aprova, em 1969, a criação de uma licenciatura intermédia, as Licenciaturas de Curta Duração, posto que as Licenciaturas Curtas não supriam a demanda de professores, principalmente no ensino das ciências, e os cursos emergenciais para realização de exame de suficiência não eram suficientes para formar pessoal qualificado para atuar nos ginásios polivalentes. No projeto de criação, o programa já traçava a pretensão de formar, até o ano de 1972, 5.841 professores nessas Licenciaturas de Curta Duração. Ou seja, era mais uma tentativa governamental de formar, em larga escala e num curto período de tempo, professores para atuarem nos ensinos ginasial e colegial, porém, dessa vez, com formação intermediária superior, pois mesmo com os cursos que já estavam sendo oferecidos, persistia o grande déficit de professores com formação adequada.

Esses novos cursos do PREMEM pretendiam formar professores para atuar no ensino de Ciências e Matemática em tempo recorde. $\mathrm{O}$ curso ocorria num período de 204 dias, ou 34 semanas de trabalho, para cumprir a carga de 1.600 horas/aula, e eram previstas para acontecer diariamente 8 horas/aulas, pela manhã e à tarde e, caso necessário, poderiam se estender até à noite. Os alunos recebiam uma bolsa para se manter e se dedicar integralmente ao curso, em contrapartida teriam o compromisso de voltar a seus Estados para lecionar nos ginásios vocacionais e atuar em qualquer uma das instituições indicada pelo programa, por um período de, pelo menos, dois anos.

Cada turma das Licenciaturas de Curta Duração seria formada por, no máximo, trinta alunos, e os cursos tinham um currículo que, 
além das disciplinas Estudos Brasileiros e Complementos de Português (obrigatórias para todos os cursos do ensino superior, à época), era formado por $60 \%$ de disciplinas de conteúdos específicos e $40 \%$ para a formação didática. Como a coordenação do programa sugeriu a criação de dois cursos para formar os professores para as áreas de ciências, uma licenciatura para os professores que atuariam no ensino de matemática e outra para os que atuariam no ensino das ciências experimentais, o programa da Licenciatura de Curta Duração em Matemática seria composto com as seguintes disciplinas: Fundamentos da Matemática Elementar, Geometria e Noções de Trigonometria e Álgebra, Noções de Geometria Analítica e Iniciação à Ciência e Ciências Físicas e Biológicas, para a parte específica, e Psicologia da Educação, Estrutura e Funcionamento do Ensino de Segundo Grau, Didática e Prática de Ensino (que incluía o estágio), para a parte pedagógica.

Além desse curso, o PREMEN14 atuou também na criação e no funcionamento do primeiro curso de pós-graduação voltado ao ensino de Ciências e Matemática, que funcionou de 1975 a 1984, sob a coordenação do Prof. Ubiratan D’Ambrosio, em parceria com a Universidade Estadual de Campinas (Unicamp/SP) e a Organização dos Estados Americanos (OEA). Trata-se do Projeto Multinacional para a Melhoria do Ensino de Matemática e Ciências (PROMULMEC) ${ }^{15}$. Esse projeto que aconteceu no estado de São Paulo fez parte, ainda, do conjunto de estratégias que atendiam aos planos MEC-USAID, à época vigente. "Com apoio do PREMEN [...], o curso de mestrado tinha características diferenciadas dos tradicionais programas de pós-graduação da época” e essas diferenças "justificavam-se pelo aumento na demanda por profissionais em um contexto de transformação tanto das orientações e metodologias para o ensino quanto do papel da ciência no mundo" (CURY, 2007, p.166).

\footnotetext{
${ }^{14}$ No ano de 1972, pelo decreto de número 70.067, é criado o Programa de Expansão e Melhoria do Ensino (PREMEN), que absorvia e ampliava a proposta do PREMEM. Assim, nos referiremos a ambos os programas PREMEM e PREMEN - dependendo do contexto ao qual nos remetemos.

${ }^{15}$ Para maiores informações sobre este curso de Pós-Graduação, ver Cury (2011) e Silva (2007).
} 
Com relação aos ginásios polivalentes, na primeira etapa do projeto do PREMEM, foram construídos 272 desses ginásios, distribuídos da seguinte forma: 51 na Bahia; 36 no Espírito Santo; 95 em Minas Gerais; 90 no Rio Grande do Sul e 1 ginásio modelo em cada uma das outras capitais. Nos quatro primeiros estados, o PREMEM firmou convênio com as Universidades para que realizassem a Licenciatura de Curta Duração.

No Nordeste, foi em 1971 que "o PREMEM fechou convênio com a Universidade Federal de Pernambuco para a realização de um Curso de Licenciatura em Ciências e em Matemática" (MELO, 1982, p. 17) para formar 120 licenciados, com o objetivo de prover os ginásios polivalentes das capitais de Pernambuco, Rio Grande do Norte, Sergipe, Alagoas, Paraíba, Ceará, Maranhão, Piauí, Amazonas, Pará, Mato Grosso, Goiás e Distrito Federal - vale lembrar que os estados de Goiás e de Mato Grosso ainda não haviam sido divididos.

Na UFPE, o CECINE foi o órgão responsável pela realização desses cursos. Esse acordo entre a UFPE, o CECINE e o PREMEM (posterior PREMEN) foi renovado até 1976, formando um total de 755 pessoas ${ }^{16}$. Do Rio Grande do Norte, foram 62 professores formados pelo curso de Licenciatura de Curta Duração desses programas, realizado pelo CECINE (MELO, 1982, p. 17); desses, 21 se formaram no ano de 1974, 04 no ano de 1975 e 05 em $1976^{17}$.

Da cidade de Mossoró, o professor Raimundo Melo, já citado, foi um dos professores formados neste curso e lembra que tinha uma duração de um ano e dois meses, com uma carga horária de mil e duzentas horas de aulas de conteúdos matemáticos, para os níveis ginasial e colegial. O conteúdo era todo da Matemática Moderna: conjuntos, propriedades de conjuntos, operações, funções etc.

\footnotetext{
${ }^{16}$ Ver ata de conclusão da primeira edição do curso e lista das cinco turmas concluintes do curso de Licenciatura de Curta Duração em Ciências e Matemática no Tomo Travessias (Registros $C M, C N, C O, C P, C Q$ e $C R$ ).

${ }_{17}$ Nos documentos que listam os concluintes desses cursos, não consta a divisão dos formados por estados nos anos de 1972 e 1973.
} 
Em Caicó, no Colégio Diocesano Seridoense, por exemplo, pelo menos dois professores possuíam, como habilitação para lecionar, o curso de Licenciatura de Curta Duração oferecido pelo CECINE e, desses, um ensinava matemática ${ }^{18}$. Além deles, participou ainda o professor Almir da Costa Dantas ${ }^{19}$.

O professor lembra que, por ser oferecido para as regiões Norte e Nordeste do país, estudou com pessoas de vários outros estados, mas também entrou em contato com outros alunos de diferentes cidades do Rio Grande do Norte, como Caicó, Mossoró, Santa Cruz, Natal e Patu. Era um curso dado simultaneamente para todos esses locais, cujas salas eram organizadas por ordem alfabética, cada uma tendo entre 45 e 50 alunos e, no geral, cerca de quatrocentas pessoas matriculadas.

O professor recorda que a seleção acontecia por estado, como um vestibular, e o número de vagas era limitado. O processo seletivo era aberto a quem quisesse participar, não sendo necessário já atuar como professor, e cada um dos aprovados e convocados ganhava uma bolsa para fazer o curso em Recife. Na Universidade Federal de Pernambuco (UFPE), onde o curso era realizado, os cursistas tinham as mesmas regalias que os alunos da universidade, além dos professores serem também da UFPE. A carga horária era de 1.650 horas e o funcionamento do curso era por sistema de créditos e disciplinas; intensivo, com aulas nos turnos matutino e vespertino, e os alunos praticamente não tinham férias: encerrada uma disciplina, iniciava-se outra. Tiveram apenas um período de recesso de oito ou quinze dias e, após esse, Almir recorda que muitos alunos não retornaram para continuar a formação.

Esse curso foi dado entre agosto de 1974 e dezembro de 1975, e Almir narra que não foi da primeira turma desse curso. Ele lembra que não tentou ingressar antes porque ainda não havia concluído o científico. Cada etapa do curso só se iniciava após o fim da anterior e funcionava dessa forma por não

\footnotetext{
${ }^{18}$ Ver os Quadros Demonstrativos dos Professores do CDS (Registros X, Y e Z no Tomo Travessias).

${ }^{19}$ A narrativa do professor Almir pode ser acessada na íntegra em Morais (2017).
} 
haver espaço para atender mais de uma edição simultaneamente, segundo aponta Almir, lembrando ainda que não existia prorrogação do tempo do curso: os alunos tinham que terminar no ano e meio de curso.

Almir narra que a estrutura do curso era excelente, com as aulas práticas em laboratórios, dos quais diz que o melhor era o de ciências, no qual realmente desenvolviam pesquisas. O professor lembra que as disciplinas desse curso eram parecidas com as do PIPEM, disciplinas voltadas para o ensino, e buscavam preparar o professor para ensinar no nível do ginásio e científico. Várias dessas disciplinas foram aproveitadas quando Almir retornou a Natal, como, por exemplo, Fundamentos da Matemática, Psicologia do Ensino, Estudo dos Problemas Brasileiros (EPB) e Prática de Ensino. Na Prática de Ensino, ao final do curso, os alunos tinham que estagiar em colégios; Almir ministrou aulas em um colégio que ficava na praia de Boa Viagem.

Por tudo o exposto, o CECINE representou para o Rio Grande do Norte, entre as décadas de 1960 e 1980, um importante lócus de formação. Por sua abrangência de atuação - Norte e Nordeste - vale apontar que sua relevância não cessa aí. Outros trabalhos como os de Macena (2013), Fernandes (2011) e Finato, Baraldi e Morais (2012) trazem indícios de como esse centro atuou na formação de professores nos estados da Paraíba e do Maranhão, ou ainda Both (2014), que apresenta indícios da atuação desse centro na formação de professores do Mato Grosso, ou seja, da região Centro Oeste.

\section{Alguns apontamentos gerais}

Como podemos perceber a partir do exposto, o CECINE, apesar de ser pouco conhecido quando tratamos da história da formação de professores no Brasil, ocupou espaços centrais nesse processo, notadamente no que tange à formação de professores que atuavam/atuariam no ensino de ciências naturais e Matemática. 
Para atuar no ensino de Matemática, especificamente, o centro ofertou formação desde o ano de sua fundação, 1965, pautado nos preceitos da Matemática Moderna, tão fortemente difundido à época pelas políticas públicas e por grupos de estudos e pesquisas sobre o ensino de matemática que começavam a surgir.

$\mathrm{Na}$ década de 1970, o CECINE vai atuar mais fortemente na formação de professores no curso de Licenciatura de Curta Duração em Ciência (que se difere da Licenciatura Curta amplamente conhecida na História da Educação brasileira), a partir de uma parceria com o PREMEM (posteriormente PREMEN).

Vale registrar que, com este artigo, não temos a pretensão de completude sobre o tema. Ao contrário, buscamos lançar luz sobre uma temática ainda pouco explorada pela História da Educação (Matemática) brasileira, que é o impacto dos CECIs, em particular o CECINE, na formação e atuação dos professores de matemática.

\section{Referências}

ABRANTES, A. C. S. Ciência, Educação e Sociedade: o Caso do Instituto Brasileiro de Educação, Ciência e Cultura (lbecc) e da Fundação Brasileira de Ensino de Ciências (Funbecc). Tese de doutorado do Curso de Pósgraduação em história das Ciências e da Saúde da Casa de Oswaldo Cruz/Fiocruz. Rio de Janeiro. 2008.

BARALDI, I. M. Retraços da Educação Matemática na Região de Bauru (SP): uma história em construção. 2003. 241 f. Tese (Doutorado em Educação Matemática) - Instituto de Geociências e Ciências Exatas, Universidade Estadual Paulista, Rio Claro (SP), 2003.

BARALDI, I. M.; GAERTNER, R. Textos e contextos: um esboço da CADES na história da educação (matemática). Blumenau: Edifurb, 2013.

BOTH, B. C. Sobre a formação de professores de matemática em Cuiabá MT (1960-1980). 2014. 402 p. Dissertação (Mestrado em Educação Matemática) - Instituto de Geociências e Ciências Exatas, Universidade Estadual Paulista, Rio Claro (SP), 2014. 
BRITO, A. J.; CRUZ, S.S. L.; FERREIRA, J. P. C. A inserção do Movimento da Matemática Moderna na UFRN. Diálogo Educacional. PUCPR. V. 6. (18). p. 91 a 100. maio/agosto. 2006. DOI: https://doi.org/10.7213/rde.v6i18.3310.

BRITO, A. J.; GUTIERRE, L. S. A formação de professores que ensinavam matemática no Rio Grande do Norte entre 1960 e 1970: o convênio SUDENE/USAID. In: Encontro Nacional de Educação Matemática, 9., 2007, Belo Horizonte. Anais..., Belo Horizonte: [s.n.], 2007.

COUSIN, A. O. A. O Movimento da Matemática Moderna nos Boletins da Sociedade Paranaense de Matemática. Revista Diálogo Educacional (PUCPR. Impresso) , v. 11, p. 751-768, 2011. DOI:

https://doi.org/10.7213/rde.v11i34.4489.

CURY, F. G. Uma História da Formação de Professores de Matemática e das Instituições Formadoras do Estado do Tocantins. Rio Claro, 2011. 289f. Tese (Doutorado em Educação Matemática) - Instituto de Geociências e Ciências Exatas, Universidade Estadual Paulista, Rio Claro (SP), 2011.

CURY, F. G. Uma narrativa sobre a formação de professores de Matemática em Goiás. Rio Claro, 2007. 201f. Dissertação (Mestrado em Educação Matemática) - Instituto de Geociências e Ciências Exatas, Universidade Estadual Paulista, Rio Claro (SP), 2007.

FERNANDES, D. N. Sobre a formação do professor de Matemática no Maranhão: cartas para uma cartografia possível. Rio Claro, 2011. 388f. Tese (Doutorado em Educação Matemática) - Instituto de Geociências e Ciências Exatas, Universidade Estadual Paulista, Rio Claro (SP), 2011.

FINATO, J. A. R.; BARALDI, I. M.; MORAIS, M. B. CADES: um ensaio sobre uma formação de professores de Matemática. Perspectivas da Educação Matemática, v. 5, p. 88-100, 2012.

GARNICA, A. V. M. (Org.). Cartografias Contemporâneas: Mapeando a Formação de Professores de Matemática no Brasil. 1ed.Curitiba: Appris, 2014.

GARNICA, A. V. M.; FERNANDES, D. N.; SILVA, H. Entre a amnésia e a vontade de nada esquecer: notas sobre regime de historicidade e história oral. Bolema (Rio Claro), v. 25, nº 41, p. 213-250, 2011.

GARNICA, A. V. M. (Org.). Oral History and Mathematics Education. 1ed. Cham (Alemanha): Springer, 2019.

GUTIERRE, L. S. O ensino da Matemática no Rio Grande do Norte (19501980): trajetória de uma modernização. 2008. 150 f. Tese (Doutorado) UFRN, Natal, 2008. 
LIMA, F. R. Grupo de Estudo do Ensino de Matemática - GEEM: Formação de Professores e o Movimento da Matemática Moderna no Brasil.

Dissertação (Mestrado em Educação Matemática). Ponfitifícia Universidade Católica de São Paulo, São Paulo, 2006.

MACENA, M. M. M. Sobre formação e prática de professores de Matemática: estudo a partir de relatos de professores, década de 1960, João Pessoa (PB). Tese (Doutorado em Educação Matemática) - Instituto de Geociências e Ciências Exatas, Universidade Estadual Paulista, Rio Claro (SP), 2013.

MAURÍCIO, L. A. Centro de Ciências: origens e desenvolvimento - uma relação sobre seu papel e possibilidades dentro do contexto educacional. Dissertação de mestrado em Educação no Instituto de Física/Faculdade de Educação USP, São Paulo. 1992.

MELO, P. B. Minhas memórias da Faculdade de Ciências Econômicas de Mossoró. Mossoró: ESAM/FGD, 1982.

MIRANDA, B. C. B. A CADES e um novo modelo de professor secundário nas décadas de 1950 e 1960. 2019. Tese (Doutorado em Educação Matemática) - Instituto de Geociências e Ciências Exatas, Universidade Estadual Paulista, Rio Claro (SP), 2019.

MORAIS, M. B. Peças de uma história: formação de professores de matemática na região de Mossoró/RN. Dissertação (Mestrado em Educação Matemática) - Instituto de Geociências e Ciências Exatas, UNESP, Rio Claro, 2012.

MORAIS, M. B. Se um viajante... Percursos e Histórias sobre a formação de professores de matemática no Rio Grande do Norte. Tese (Doutorado em Educação Matemática) - Instituto de Geociências e Ciências Exatas, UNESP, Rio Claro, 2017.

SEARA, H. F. Núcleo de Estudo e Difusão do Ensino da MatemáticaNEDEM - "Não é Difícil Ensinar Matemática”. 2005. 228 f. Dissertação (Mestrado) - Setor de Educação, Universidade Federal do Paraná, Curitiba, 2005.

SILVA, B. C. Breve história do CECINE: como a ciência virou dúvida e investigação. 2012 (mímeo)

SILVA, H. Centro de Educação Matemática (CEM): fragmentos de identidade. Rio Claro, 2006. 480f. Tese (Doutorado em Educação Matemática) - Instituto de Geociências e Ciências Exatas, Universidade Estadual Paulista, Rio Claro (SP), 2007. 
SOUZA, L. A.; GARNICA, A. V. M. Movimentos de um Movimento: um estudo sobre os significados atribuídos ao escolanovismo e seus ritmos. Educação Matemática Pesquisa (Online), v. 14, p. 481-506, 2012.

UNESCO. Brazil - National Centre for Research and Development in Science Teaching. Paris, August 1968.

VALENTE, W. R. A Matemática Moderna nas Escolas do Brasil: Um Tema Para Estudos Históricos Comparativos. Revista Diálogo Educacional, v. 6, n. 18, p. 19-34, 2006. DOI: https://doi.org/10.7213/rde.v6i18.3214.

VALENTE, W. R. Osvaldo Sangiorgi e o Movimento da Matemática Moderna no Brasil. Revista Diálogo Educacional, v. 8, n. 25, p. 583-613, set./dez. 2008. DOI: https://doi.org/10.7213/rde.v8i25.3724. 